\title{
O VALOR SOCIAL GERADO POR EMPRESAS SOCIAIS: REFLEXÕES A PARTIR DE UMA META-SÍNTESE
}

\author{
Indira Gandhi Bezerra-de-Sousa \\ Doutoranda em Administração \\ Universidade Federal do Paraná - Curitiba/PR - Brasil \\ indirabs16@gmail.com - https://orcid.org/0000-0001-7072-1514 \\ Rodrigo Luiz Morais-da-Silva \\ Doutor em Administração \\ Universidade Federal do Paraná - Curitiba/PR - Brasil \\ rodrigolms.silva@gmail.com - http://orcid.org/0000-0003-4365-519X \\ Adriana Roseli Wunsch Takahashi \\ Doutora em Administração \\ Universidade Federal do Paraná - Curitiba/PR - Brasil \\ adrianarwt@gmail.com - http://orcid.org/0000-0002-4738-5273 \\ Andréa Paula Segatto \\ Doutora em Administração \\ Universidade Federal do Paraná - Curitiba/PR - Brasil \\ andreapsegatto@gmail.com - https://orcid.org/0000-0002-8903-9256
}

\section{RESUMO}

As empresas sociais estão ganhando destaque no mercado e notoriedade no ambiente acadêmico por criarem produtos e serviços que geram valor social com foco na resolução de problemas da sociedade. No entanto, devido à contemporaneidade do tópico, ainda existem lacunas teóricas a serem abordadas. Uma delas está relacionada à forma como o valor social é gerado pelas empresas sociais. Esse ponto específico deu origem ao objetivo deste estudo que é analisar como as empresas sociais podem criar e potencializar o valor promovido à sociedade. No que se refere ao método empregado, utilizou-se a meta-síntese como estratégia de pesquisa, seguindo os passos de Hoon (2013), cujo objetivo é extrair, analisar e sintetizar evidências de estudos de casos qualitativos para construir teoria. A fim de cumprir os objetivos da pesquisa, inicialmente, foram analisados 44 artigos identificados nas bases de dados internacionais, Web of Science e Scopus, e nacionais, Spell e Scielo, sendo oito deles selecionados para comporem a análise do estudo. Os achados desta pesquisa podem ser sintetizados na proposta de cinco elementos que contribuem para a criação e a potencialização do valor social no contexto de empresas sociais, sendo eles: i) envolvimento com stakeholders; ii) mobilização de recursos; iii) cultura centrada na inovação; iv) planejamento estratégico aliado à missão social e ao valor econômico e; v) marketing - foco no beneficiário/consumidor. Assim, os resultados encontrados desvelam informações úteis sobre a relevância da criação de valor pelas empresas sociais, bem como apresentam cinco elementos que representam atitudes, comportamentos e estratégias latentes para o alcance do impacto social.

Palavras-chave: Criação de valor social. Empresa social. Meta-síntese. Revisão de literatura.

\section{SOCIAL VALUE GENERATED BY SOCIAL ENTERPRISES: REFLECTIONS FROM A META-} SYNTHESIS

\begin{abstract}
Social enterprises are gaining prominence in the market and notoriety in the academic context by creating products and services that create social generate social value with a focus on solving society's problems. However, due to the contemporaneity of the topic, there are still theoretical gaps to be addressed. One is related to the generation of social value by social enterprises. This specific subject motivated the development of this study, which aims to analyze how social enterprises can create and enhance the social value promoted to society. Regarding the method employed, the meta-synthesis was used as a research strategy, following the steps of Hoon (2013), which aims to extract, analyze and synthesize evidence from qualitative case studies to build theory. In order to meet the research objectives, initially, 44 articles identified in the international, Web of Science and Scopus, and national, Spell and Scielo, were analyzed, eight of them were selected to compose the sample of this study. The findings of this research can be summarized in the proposal of five elements that contribute to the creation and enhancement of social value in the context of social enterprises: i) involvement with stakeholders; ii) resource mobilization; iii) culture focused on innovation; iv) strategic planning combined with social mission and economic value; v) marketing - focus on the beneficiary / consumer. Thus, the findings reveal useful information on the relevance of value creation by social companies, as well as five elements that represent latent attitudes, behaviors and strategies for achieving social impact.
\end{abstract}

Key words: Creation of social value. Literature review. Meta-synthesis. Social enterprise.

Data da submissão: $21 / 02 / 2019$

Data de aceite: $16 / 01 / 2020$

Revista de Gestão Social e Ambiental - RGSA, São Paulo, v. 13, n. 2, p. 75-92, maio/ago. 2019. 


\section{INTRODUÇÃO}

Desde o final da década de 1990, estudos sobre empresas sociais se tornaram uma tendência nos Estados Unidos e Europa, além do caso particular do Brasil. A partir disso, a compreensão sobre empresa social, embora ainda não seja consenso, cresceu rapidamente pela contribuição que esse tipo de empreendimento pode gerar, principalmente para pessoas que vivem abaixo da linha da pobreza (Smith, Gonin \& Besharov, 2013). Nessa perspectiva, entende-se que empresa social é uma atividade que pretende resolver um problema social e/ou ambiental complexo, a partir de uma lógica de mercado (Dacin, Dacin \& Tracey, 2011; Battilana \& Lee, 2014), sendo a principal diferença entre esse tipo de empresa e a empresa tradicional, a motivação na transformação social positiva causada intencionalmente pelo primeiro tipo (Mair \& Marti, 2006; Austin, Stevenson \& Wei-Skillern, 2006; Dacin et al. 2011).

De modo específico, empresa social é a combinação da lógica filantrópica com a lógica econômica (Thompson, 2008), por isso são chamadas de organizações híbridas que utilizam múltiplas formas de organização (Battilana \& Lee, 2014) e de operações empresariais. Também são autossustentáveis financeiramente, de modo que asseguram o desenvolvimento, a sustentação, o arranjo e a propagação do valor social e/ou ambiental (Mulyaningsih \& Dhewanto, 2013; Battilana \& Lee, 2014). Compreende-se, então, que as empresas sociais são criativas, diante do seu potencial de inovar (Thompson, 2008), e está, essencialmente, relacionada à consciência social (Mulyaningsih \& Dhewanto, 2013) e à criação de valor.

Como a criação de valor é uma parte importante desse tipo de empreendimento (Mair \& Marti, 2006; Islam, 2017), esta pesquisa tem um interesse particular nesse assunto, principalmente porque ainda não se tem uma compreensão abrangente de como as empresas sociais geram valor social (Battilana \& Lee, 2014). Sendo esse, um tema emergente e significativo na pesquisa de empreendedorismo social (Smith et al., 2013), estudos precisam ser realizados sobre esse tópico.

Pesquisas anteriores já discutiram sobre esse assunto, analisando diferentes aspectos. Islam (2017) buscou entender se a divulgação da criação de valor social se torna uma estratégia importante para a legitimação das empresas sociais; Altinay, Sigala e Waligo (2016) demonstraram como empresas sociais de turismo e hospitais podem gerar valor social; e Knife, Haughto e Dixon (2014) estudaram, de forma teórica, como as empresas sociais são sustentáveis na geração e manutenção da estratégia de criação de valor. Embora haja estudos sobre os tópicos, pode-se perceber que são contribuições com focos delimitados e que não preenchem a lacuna de pesquisa entre a atuação de empresas sociais e a criação de valor social.

Nesse sentido, este artigo pretende responder o seguinte problema: Como as empresas sociais podem criar e potencializar o valor social promovido à sociedade? Para isso, utilizou-se a técnica de meta-síntese, que implica na extração e na análise de insights de estudos de casos primários, com o intento de identificar categorias e padrões para construir teorias mais robustas (Hoon, 2013).

As descobertas deste estudo contribuem para a literatura sobre empresas sociais e valor social de pelo menos três modos. Em primeiro lugar, o trabalho fornece informações relevantes a respeito da importância do valor social criado pelas empresas sociais, aprofundando o conhecimento sobre tais assuntos, demonstrando mais claramente como os conceitos estão relacionados. A segunda contribuição deste artigo está associada à identificação de cinco dimensões que representam atitudes, comportamentos e estratégias de como as empresas sociais podem potencializar a criação de valor social. Por fim, a terceira contribuição reside ao sintetizar a resposta do problema de pesquisa em elementos norteadores e na criação de um modelo teórico, servindo

$\overline{\text { Revista de Gestão Social e Ambiental - RGSA, São Paulo, v. 13, n. 2, p. 75-92, maio/ago. } 2019 .}$ 
como base para outros pesquisadores os investigarem de forma isolada ou testando-os no campo empírico.

\section{EMPRESA SOCIAL}

Antes de adentrar nas especificações sobre empresa social, cabe destacar um amplo campo que se relaciona a esses negócios: o empreendedorismo social. Embora essa área tenha auferido maior notoriedade desde a década de 1990, ainda não se desfruta de um consenso conceitual sobre o fenômeno (Austin et al., 2006; Thompson, 2008; Choi \& Mamjudar, 2014; Sengupta \& Sahay, 2017). Um dos conceitos mais difundidos é o de Austin et al. (2006, p. 2, tradução nossa), que compreendem o empreendedorismo social com uma "[...]uma atividade inovadora, criadora de valor social que pode ocorrer dentro ou entre os setores sem fins lucrativos, empresariais ou governamentais".

Nessa perspectiva, imerso ao campo do empreendedorismo social, as empresas sociais se configuram como organizações híbridas marcadas pela pluralidade de nomenclaturas (Comini, 2016), quais sejam: empresas sociais, negócios sociais, negócios inclusivos e negócios de impacto social. Essa diversidade de termos está atrelada à complexidade dessa forma organizacional (Choi \& Mamjudar, 2014; Comini, 2016), somada às distintas abordagens, que geram uma certa indefinição ao classificar o termo correto a ser utilizado. Buscando sistematizar os termos e abordagens utilizados, Comini (2016) os diferencia de acordo com os contextos nos quais estão imersos, levando a criação de três perspectivas: a europeia, a americana e a dos países emergentes.

$\mathrm{Na}$ perspectiva europeia, o termo jurídico utilizado é 'empresa social' (social enterprise), surgido em 1980, a fim de representar as empresas orientadas à missão social (Domenico, Haugh \& Tracey, 2010). É importante esclarecer que sua finalidade é produzir produtos e serviços comercialmente viáveis com um custo mais baixo (Thompson, 2008; Comini, Barki \& Aguiar, 2012), no qual são realizadas atividades de negociação, voltada para missão social, orientadas à geração de benefícios sociais e à solução de problemas que interferem na qualidade de vida da sociedade.

Já a perspectiva americana utiliza o termo iniciativa social (social venture) (Comini, 2016), assim como negócio social (social business) (Comini et al., 2012), como termos abrangentes capazes de incluir multinacionais, corporações e empresas limitadas, sem finalidade lucrativa (Defourny \& Nyssens, 2010). Estão voltadas para a produção de produtos e prestação de serviços para a base da pirâmide (BoP), ou seja, as pessoas de baixo poder aquisitivo (Prahalad, 2005). Ademais, possuem objetivos sociais que podem englobar uma empresa tradicional (multinacionais).

Por último, a perspectiva dos países emergentes utiliza com maior frequência o termo negócio social nos países asiáticos (Comini et al., 2012) e negócio inclusivo nos países latinoamericanos (Comini, 2016). Os negócios sociais seguem o direcionamento da proposta de Mohhamad Yunus, prevendo que o empreendimento deve ser sustentável e rentável, embora o lucro deva ser reinvestido totalmente na organização, ou distribuído aos sócios, se caso forem integrantes da população carente, a fim de melhorar a qualidade de vida deles e, assim, saírem da pobreza (Yunus, Moingeon \& Lehmann-Ortega, 2010). Já nos negócios inclusivos, a proposta é incluir os mais pobres tanto no processo produtivo, quanto no consumo (Márquez; Reficco, Berger \& 2009; Rosolen, Tiscoski \& Comini, 2014).

Existe ainda mais uma terminologia não presente nas perspectivas propostas por Comini (2016) denominada de negócios de impacto social (NIS). Embora mais utilizada e difundida no contexto brasileiro, ainda é incipiente. São organizações que anseiam pelo impacto social, a partir da comercialização de produtos e serviços que atendam às necessidades sociais da população de baixa renda almejando retorno financeiro (Barki, 2015). Quanto à lucratividade, esses negócios não

Revista de Gestão Social e Ambiental - RGSA, São Paulo, v. 13, n. 2, p. 75-92, maio/ago. 2019. 
condicionam a distribuição de lucros aos acionistas ou ao reinvestimento da organização. Logo, fica a critério da gestão da organização tratar sobre essa definição (Pessanha, 2014; Barki, 2015).

Após apresentar a caracterização de cada uma das nomenclaturas utilizadas em seus distintos contextos, compreende-se que a diversidade de termos pode ser justificada pela configuração de cada negócio em diferentes regiões do mundo, no qual estão imersos em contextos econômicos, sociais e políticos diferentes (Rosolen et al., 2014). Diferenciam-se também em relação à lucratividade e no direcionamento dos produtos e serviços. Respaldado nisso, é justo considerar que as terminologias possuem características e objetivos semelhantes.

No geral, os termos supracitados representam organizações voltadas para a melhoria das condições de vida da população, particularmente daquela parcela que possui menor poder aquisitivo, e que orientam sobre a conservação ambiental, impulsionam o ato de empreender, buscam escalabilidade do produto e/ou serviço desenvolvido, dispõem como objetivo central a geração de valor social, buscam a mensuração do impacto social e apresentam uma lógica econômica de mercado (Yunus et al., 2010; Comini, 2016).

Embora existam distintas perspectivas que permeiam o conceito, é necessário a escolha de um termo para a escrita do artigo, assim, optou-se pela 'empresa social', por ainda ser o mais difundido na literatura mundial, bem como por essa escolha não afetar a condução e operacionalização da pesquisa. Adicionalmente, independente das perspectivas, todas elas explicitam que a missão central da proposta é a criação de valor social, tema que foi discutido no tópico seguinte

\section{Criação de valor social em empresas sociais}

A complexidade ao definir o termo valor social no campo das empresas sociais se deve às suas distintas abordagens e perspectivas (Altinay et al., 2016). Isso se intensifica no campo do empreendedorismo social porque ainda pouco se sabe sobre como o valor social pode ser gerado (Lepak, Smith \& Taylor, 2007; Altinay et al., 2016; Singh, 2016; Sigala, 2016). Três causas caracterizam tal entendimento: i) A falta de consenso na definição; ii) A amplitude e multidisciplinaridade do termo; iii) A falta de conteúdo sobre como o valor social é gerado e; iv) O conflito entre geração de valor e captura de valor (Lepak et al., 2007).

Nesse sentido, o que se caracteriza como valor social em um contexto pode diferir de outro devido aos aspectos econômicos, sociais, políticos e ambientes institucionais. Logo, o valor social gerado por empresas de países desenvolvidos e por empresas de países em desenvolvimento podem ter conceitos diferentes (Acs, Boardman \& Mcneely, 2013). Isso é justificado porque o contexto possui uma forte influência no empreendedorismo social, por isso que diferentes fatores contextuais interferem na criação de valor social (Singh, 2016).

Embora constate-se uma variedade de concepções, o valor social aqui entendido é o objetivo final gerado pelas empresas sociais, ou seja, trata-se da solução de questões que afetam diretamente ou indiretamente grande parte da sociedade (Di Domenico, Haugh \& Tracey, 2010). Esse objetivo resume-se na mudança na vida das pessoas, seja na geração de renda, na promoção do acesso a produtos para baixa renda, promoção de saúde, educação, habitação, financiamento, emprego e na melhoria de qualidade de vida da população. Desse modo, para que esse valor seja criado, é necessário identificar e ter um profundo conhecimento do problema/necessidade a ser resolvido (Sinkovics, Sinkovics \& Yasmin, 2018), sendo geralmente uma ideia inovadora (Singh, 2016). Para isso, o empreendedor social se torna o ator principal para alcançar esse objetivo.

Salienta-se que, embora a empresa social tenha uma missão social explicita, não significa que, necessariamente, a criação de valor social é um resultado incontestável. Porém, por diversas condições, entre elas, sua flexibilidade (Di Domenico et al., 2010), e sua adaptabilidade, por estar

$\overline{\text { Revista de Gestão Social e Ambiental - RGSA, São Paulo, v. 13, n. 2, p. 75-92, maio/ago. } 2019 .}$ 
em ambientes carentes de recursos e pela sua configuração de atuar, existe uma maior facilidade em criar algo que mude sistemicamente a vida das pessoas (Sinkovics et al., 2018).

Embora haja essa facilidade, a criação de valor social é um processo que pode ser difícil (Son, Lee \& Chung, 2018) e que depende de diversos fatores. Assim, destaca-se a improbabilidade das empresas sociais gerarem valor social se não for por meio do engajamento com todas as partes envolvidas, sendo eles, consumidores, produtores, empreendedores, colaboradores (Sinkovics et al., 2018) governo (Son et al., 2018), comunidades e stakeholders de uma forma geral (Altinay et al., 2016. O engajamento de todas essas partes, seja por intermédio de parcerias, alianças, consultorias, colaboração, interação ou apenas para firmar um contato, facilita o processo de criação de valor social (Ramus \& Vacaro, 2017; Henry, 2015). Com isso, operar a partir de uma estratégia de rede é sempre o mais efetivo para alcançar o objetivo final (Di Domenico et al., 2010)

Adicionalmente a essa estratégia, as empresas sociais devem acessar e se envolver com esses grupos para fomentar a troca de recursos e a integração de processos (Altinay et al., 2016), bem como esses grupos devem participar de estratégias da empresa para garantir um bom nível de desempenho financeiro e, consequentemente, gerar o valor social (Liu, Eng \& Takeda, 2015). Ainda, deve-se acumular ativos relacionais, garantir que o produto/serviço alcance o nível de simplicidade, usabilidade e padronização (Son et al, 2018), criar dinamicamente os recursos (Di Domenico et al. 2010) e desenvolver capacidade de adaptação (Knife, Haughton \& Dixon, 2014).

Embora existam fatores que influenciam à resolução do problema social, há também aqueles que limitam e dificultam esse processo. Desse modo, pode ser apontada a dificuldade de acesso a matérias-primas, a falta de investimento financeiro, de equipamentos e infraestrutura, a inexistência de educação e de formação em empreendedorismo, a ausência de capacidade de se relacionar diretamente com compradores, a falta de compradores consistentes (London, Anupindi \& Sheth, 2010), a supressão de apoio do governo, a ausência de pesquisa e desenvolvimento e serviços inadequados de informação, a falta de tecnologia (Chowdhury, 2007), a ausência de conhecimento e a existência de assimetria de informações e capital humano subdesenvolvido (Dahan, Doh, Oetzel \& Yaziji, 2010).

Assim, observa-se que as empresas sociais, juntamente aos seus empreendedores, precisam ter um comportamento dinâmico diante dos desafios que os circundam para que, de fato, consigam atingir o seu objetivo final de geração de valor social. Como essas questões ainda necessitam de novas compreensões (Battilana \& Lee, 2014), este estudo busca chamar atenção para esse enfoque a partir do uso da técnica de meta-síntese.

\section{PROCEDIMENTOS METODOLÓGICOS}

Para atender o objetivo de analisar como as empresas sociais podem criar e potencializar o valor social promovido à sociedade, realizou-se uma meta-síntese baseada nos fundamentos de Hoon (2013). A meta-síntese é um método, exploratório e indutivo, de revisão teórica que vai além de revisões sistemáticas por tentar extrair, analisar e sintetizar evidências qualitativas para construção de teorias. A intenção não é apenas sintetizar e a apresentar os resultados das evidências encontradas nos estudos, mas identificar padrões e diferenças nos resultados, chegando a diferentes conclusões.

A operacionalização desse método reside na identificação de estudos de casos sobre um mesmo fenômeno no intento de contribuir substantivamente com o desenvolvimento de conhecimento, permitindo alcançar contribuições além das encontradas nos estudos originais. Para isso, Hoon (2013) divide a preparação da meta-síntese em oito passos apresentados na sequência: i) Enquadramento da questão de pesquisa (identificação da questão de pesquisa no campo de estudos em empresas sociais, mais especificamente, na área de valor social); ii) Localização de pesquisas

Revista de Gestão Social e Ambiental - RGSA, São Paulo, v. 13, n. 2, p. 75-92, maio/ago. 2019. 
relevantes (identificação de pesquisas pertinentes para a questão de pesquisa); iii) Definição de critérios de inclusão e exclusão dos artigos (delimitação de quatro critérios de inclusão e exclusão para a seleção final dos artigos); iv) Extração e codificação dos dados (leitura aprofundada do conteúdo particular de cada estudo e codificação das informações conforme objetivos da metasíntese); v) Análise em nível específico de cada caso (análise particular sobre a forma como cada caso de empresa social gera valor social); vi) Realização da síntese dos artigos a partir de um nível transversal (as redes causais específicas dos casos foram mescladas em uma rede meta-causal, buscando um padrão geral entre os constructos encontrados); vii) Construção da teoria a partir da meta-síntese (identificação de um padrão geral sobre como as empresas sociais podem gerar e potencializar o valor social, demonstrando uma contribuição significativa); viii) e realização da discussão (discussão dos resultados do estudo da meta-síntese e limitações potenciais).

Essa breve descrição de cada um dos passos delimitados por Hoon (2013), bem como a forma de execução nesse estudo, buscaram apresentar o método e o modo de sua consecução nesta meta-síntese.

$\mathrm{Na}$ primeira etapa, estudou-se, de uma forma geral, a literatura existente sobre empresas sociais e valor social, definindo o problema norteador dessa meta-síntese: como as empresas sociais podem criar e potencializar o valor social?

No passo a seguir, dando início à segunda etapa, buscaram-se estudos que correspondessem ao tema de interesse (empresas sociais e valor social). Isso foi realizado a partir da escolha das bases de dados internacionais e nacionais. As internacionais foram Web of Science e Scopus, utilizando as palavras-chave "social enterprise" AND "social value", enquanto as nacionais foram Spell e Scielo, empregando os termos: "empresa social" AND "valor social", sem data de restrição em nenhuma das bases escolhidas. Após essas definições, realizou-se a primeira busca na Web of Science, utilizando os seguintes filtros: 'topic, article e 'business and management' constatando 17 artigos. Na Scopus, empregou-se os filtros: 'article title, abstract and keyword', 'business, management and accounting' e 'article', finalizando como 42 trabalhos. No entanto, observaram-se 14 artigos repetidos, portanto, excluídos da análise.

$\mathrm{Na}$ fase de seleção dos artigos nacionais, iniciou-se a busca pela Spell, utilizando apenas 'palavras-chave' como filtro, encontrando um artigo teórico. Como o objetivo do artigo é a busca de estudo de casos, de imediato foi excluído da análise. Em seguida, realizou-se a busca na Scielo com os seguintes filtros 'resumo e negócios', finalizando com um artigo teórico, logo sendo também eliminado da meta-síntese. Assim, para fase de análise foram selecionados 44 artigos.

Ao selecionar os 44 artigos, fez-se necessário, conforme a terceira etapa, delimitar critérios de inclusão e exclusão no intento de escolher somente aqueles consistentes com o escopo e o objetivo estabelecido anteriormente. O desenvolvimento de quatro critérios específicos para inclusão e exclusão de artigos fez parte desta etapa, quais sejam: somente artigos científicos publicados em periódicos, não havendo restrição quanto à qualificação; artigos que utilizam da estratégia de estudo de caso qualitativo; estudos que tenham como foco a empresa social e o valor social, eliminando os falsos positivos que aparecem apenas algumas vezes no texto sem ser o cerne do trabalho e; estudos que atendem aos critérios de qualidade, rigor e confiabilidade do estudo de caso.

Dos 44 artigos selecionados na etapa anterior, 36 não se encaixam nos critérios estabelecidos na Figura 1 e, assim, foram excluídos. Portanto, foram incluídos na amostra final oito publicações, conforme apresentado na Figura 1, por disporem de uma ligação clara entre teoria e evidência empírica e por envolverem estudos de casos únicos e múltiplos dentro do tema estabelecido.

Assim, a partir da definição da amostra final em oito estudos, iniciou-se o processo de análise.

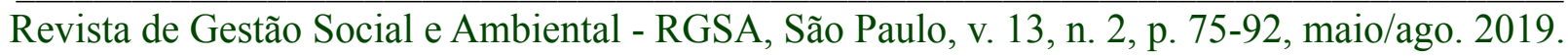




\section{ANÁLISE E DISCUSSÃO DOS RESULTADOS}

As três primeiras etapas da meta-síntese, levaram à identificação o de oito artigos que serviram de base para análise desse estudo. Os oito artigos que se enquadraram nos critérios estabelecidos podem ser visualizados na Figura 2.

\begin{tabular}{|c|c|c|c|}
\hline $\mathbf{N}$ & Título & Fonte & Periódico \\
\hline 1 & $\begin{array}{l}\text { Stakeholders matter: how social enterprises address } \\
\text { mission drift }\end{array}$ & Ramus \& Vaccaro (2017) & $\begin{array}{l}\text { Journal of Business } \\
\text { Ethics }\end{array}$ \\
\hline 2 & $\begin{array}{l}\text { Creating social value through social } \\
\text { enterprise marketing: case studies from thailand's } \\
\text { food-focused social entrepreneurs }\end{array}$ & $\begin{array}{c}\text { Srivetbodee, Igel \& } \\
\text { Kraisornsuthasinee (2017) }\end{array}$ & $\begin{array}{l}\text { Journal of Social } \\
\text { Entrepreneurship }\end{array}$ \\
\hline 3 & $\begin{array}{c}\text { The social value of rescuing food, nourishing } \\
\text { communities }\end{array}$ & $\begin{array}{l}\text { Mirosa, Mainvi, Horne \& } \\
\text { Mangan-Walker (2016) }\end{array}$ & British Food Journal \\
\hline 4 & Social value creation through tourism enterprise & $\begin{array}{l}\text { Altinay, Sigala \& Waligo } \\
\text { (2016) }\end{array}$ & Tourism Management \\
\hline 5 & $\begin{array}{l}\text { Doing well by doing good: opportunity recognition } \\
\text { and the social enterprise partnership }\end{array}$ & Henry (2015) & $\begin{array}{l}\text { Journal of Social } \\
\text { Entrepreneurship }\end{array}$ \\
\hline 6 & $\begin{array}{l}\text { Business models for people, planet (\& profits): } \\
\text { exploring the phenomena of social business, } a \\
\text { market-based approach to social value creation }\end{array}$ & Wilson \& Post (2013) & $\begin{array}{l}\text { Small Business } \\
\text { Economics }\end{array}$ \\
\hline 7 & $\begin{array}{c}\text { Social bricolage: theorizing social value creation in } \\
\text { social enterprises }\end{array}$ & $\begin{array}{l}\text { Di Domenico, Haugh } \\
\quad \& \text { Tracey }(2010)\end{array}$ & $\begin{array}{l}\text { Entrepreneurship: } \\
\text { Theory and Practice }\end{array}$ \\
\hline 8 & The study of social enterprise management & $\begin{array}{l}\text { Yang, Ben Wu, Su, Kao \& } \\
\text { Lin (2010) }\end{array}$ & $\begin{array}{l}\text { International Journal } \\
\text { of Revenue } \\
\text { Management }\end{array}$ \\
\hline
\end{tabular}

Figura 1. Artigos selecionados para meta-síntese

Fonte: Elaborado pelos autores (2018)

$\mathrm{Na}$ quarta etapa, os oito artigos selecionados foram lidos e cuidadosamente relidos no intento de codificar as características dos estudos e seus principais insights. A codificação foi feita por meio de uma planilha eletrônica, com dados gerais dos artigos e a codificação inicial das seções relacionadas com o objetivo deste estudo. Além dos dados gerais, tais como título, autor (es), ano de publicação e periódico, também foram extraídos dos artigos o objetivo geral, a aderência de referências teóricas à criação de valor social em empresas sociais, o contexto da pesquisa, as escolhas metodológicas (estratégia, instrumentos de coleta de dados, técnica de análise), principais conclusões, principais contribuições teóricas e práticas e, por fim, foi efetuada uma análise geral do artigo. Realizou-se a codificação primária dos oito estudos, obtendo características descritivas, com o intuito de facilitar a análise específica de cada artigo. Além das características descritivas, o foco maior residiu na identificação dos insights que os estudos de caso geraram.

$\mathrm{Na}$ quinta etapa, com foco na análise do nível específico, mapeou-se cada caso com o intuito de identificar e analisar categorias que poderiam estar relacionadas à geração de valor social de uma empresa social. Com isso, redes causais específicas a cada caso foram desenvolvidas, identificando temas, níveis de análise e como os resultados de cada estudo se relacionavam aos interesses da presente meta-síntese.

Após a síntese realizada individualmente de cada artigo, na sexta etapa, mesclaram-se sequências de categorias identificadas em cada uma das redes causais específicas. A intenção foi desenvolver uma rede meta-causal, capaz de englobar descobertas amplas e além das realizadas nos estudos primários. Nesse sentido, identificaram-se padrões lógicos estabelecidos entre os casos 
relativos à geração de valor social de uma empresa social. A partir dos padrões, foi possível identificar cinco categorias que respondem o problema de pesquisa ao potencializar a criação de valor social nas empresas sociais. As cinco categorias são: i) Engajamento de stakeholders; ii) Mobilização de recursos; iii) Cultura centrada na inovação; iv) Planejamento estratégico alinhado ao valor social e ao valor econômico; e v) Estratégias de marketing, conforme apresentado na Figura 3.

A rede meta-causal revelou, já como contribuição para a sétima etapa da meta-síntese, a existência de cinco elementos que auxiliam na criação e potencialização do valor social no contexto das empresas sociais. Inicialmente, encontrou-se o engajamento de stakeholders, primeiro elemento desvelado, em que representam grupos e atores interessados no desenvolvimento das empresas sociais. Esses grupos podem ser: governo, grandes empresas, empresas sem fins lucrativos, empresas sociais, empresas tradicionais, consumidores, fornecedores, financiadores e colaboradores. Quanto maior o envolvimento com esses atores, maior e mais fácil será a criação de valor social.

Essa categoria está presente em todos os estudos, e representa a importância das empresas sociais realizarem parcerias, contatos, alianças, bem como aumentarem a sua rede de contatos com a finalidade de identificar melhores oportunidades, manter seu compromisso com a missão social, obter economia financeira (Henry, 2015), adquirir habilidades técnicas e gerenciais das partes interessadas (Ramus \& Vaccaro, 2017), trocar e integrar recursos entre os atores (Altinay et al., 2016) e criar vínculos de mercado (Wilson \& Post, 2013).

No entanto, para que de fato esses grupos ajudem as empresas sociais a criarem valor social é necessário o comprometimento dos múltiplos atores (Di Domenico et al., 2010; Altinay et al., 2016; Mirosa, Mainvil, Horne \& Mangan-Walker, 2016; Ramus \& Vaccaro, 2017; Srivetbodee et al., 2017), a criação de critérios para selecionar esses grupos (Ramus \& Vaccaro, 2017), o desenvolvimento de capacidades para atrair parceiros com habilidades e capacidades crescentes (Yang et al., 2010; Ramus \& Vaccaro, 2017; Altinay et al., 2016), o diálogo com as partes interessadas, a realização de atividades experimentais com os consumidores, a criação de uma relação de confiança entre as partes (Altinay et al., 2016) e o envolvimento dos atores na criação, gestão e governança da empresa social (Henry, 2015).

Cabe destacar que a interação com os consumidores é um aspecto importante para organização entender os problemas dos quais os beneficiários estão passando. Desse modo, quanto maior a aproximação com eles, maior a criação de valor, visto que os usuários são os maiores beneficiados da atividade da empresa social (Srivetbodee et al., 2017). Portanto, as partes interessadas ajudam e potencializam a criação de valor social, permitindo que empresas sociais se insiram cada vez mais nesse ecossistema e se aproximem de parceiros que possuem propósitos semelhantes.

A segunda categoria denominada de mobilização de recursos está presente em sete estudos. Essa categoria é recorrente nas pesquisas devido ao desafio que as empresas sociais possuem quanto à escassez de ativos para produzir e se manter funcionando (Di Domenico et al., 2010; Henry, 2015). Isso inclui recursos financeiros, humanos, técnicos, administrativos e mercadológicos. Os recursos mais destacados nos estudos são os recursos financeiros e humanos (Ramus \& Vaccaro, 2017). Com isso, as empresas sociais geralmente utilizam empréstimos bancários, empréstimos de amigos e familiares e recursos pessoais para poderem desenvolver as suas atividades. Somente após a difusão da empresa é que, de fato, conseguem financiamentos de risco (Wilson \& Post, 2013). Quanto aos recursos humanos, evidências apontam que é preciso gerenciá-los de forma a atender às necessidades dos clientes em tempo hábil, com eficiência e flexibilidade. O colaborador deve ser treinado a resolver o problema para o qual ele é designado (Ramus \& Vaccaro, 2017). Complementa-se ainda que a captação dos colaboradores é substancial,

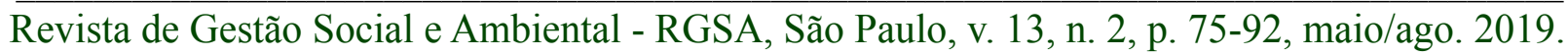


tendo em vista que a partir do momento em que o colaborador faz parte da equipe organizacional, é necessário dispor de um propósito social.

Ainda em relação à segunda categoria, os resultados dos estudos mostram a importância do compartilhamento e agrupamento de recursos disponíveis no mercado (Henry, 2015; Altinay et al., 2016), bem como de recombinar recursos internos disponíveis na organização, aproveitar recursos negligenciados e reciclar produtos descartados (Srivetbodee et al., 2017; Di Domenico et al., 2010). Nessa perspectiva, o empreendedor social é forçado a ser mais criativo para utilizar melhor os recursos e permanecer com o nível de criação de valor social.

Outro modo que as organizações podem contornar a limitação de recursos está na avaliação do ambiente antes do desenvolvimento do seu produto/serviço, ou seja, verificar quais os recursos disponíveis e trabalhar com eles (Henry, 2015). Em outras palavras, ao invés do empreendedor se preocupar de imediato em criar o produto/serviço, inicialmente ele pode analisar as capacidades, habilidades e recursos disponíveis, para assim, pensar na melhor maneira de colocá-los em uso. Em todo caso, é preciso neutralizar as restrições impostas pelo ambiente a partir de um comportamento ativo, inovador e improvisador (Di Domenico et al., 2010). Portanto, as empresas sociais devem, além de mobilizar recursos externos, integrar e criar recursos internos, bem como saber gerenciálos.

Já a terceira categoria, denominada de inovação, faz parte do cerne da empresa social, visto serem empreendimentos inovadores e eficazes (Ramus \& Vaccaro, 2017). A empresa social inovadora consegue alcançar mais facilmente o seu objetivo final na geração de valor social. Para isso, a inovatividade deve ser encarada como algo cultural e deve ser central na missão e no modelo de negócio do empreendimento (Di Domenico et al., 2010; Yang et al., 2010). Geralmente, empresas sociais tecnológicas possuem maior facilidade de inovar. Mas, de qualquer modo, os empreendedores sociais não devem subestimar a importância da inovação como um modo de obter valor social (Srivetbodee et al., 2017). Adicionalmente, dentre as inovações que as empresas sociais podem desenvolver, existe a inovação social, evidenciada em alguns dos estudos (Wilson \& Post, 2013; Henry, 2015; Srivetbodee et al., 2017), no qual remete a criação de produtos/serviços ou atividades inovadoras que atendam uma necessidade social, promovendo a criação de valor. Assim, entende-se, a partir dessa categoria, a importância do desenvolvimento de inovações alinhadas à filosofia organizacional.

A quarta categoria, planejamento estratégico, está voltada a condução e a delimitação de estratégias da empresa social a longo prazo. Esse planejamento se torna mais complexo pela necessidade em obter equilíbrio da missão social e do valor econômico. Isto se torna um desafio devido ao risco de as empresas desviarem da sua missão (Di Domenico et al., 2010; Henry, 2015; Altinay et al., 2016; Srivetbodee et al., 2017; Ramus \& Vaccaro, 2017).

Para isso, os estudos evidenciam também que há uma necessidade de controlar as pressões do ambiente interno e externo (Ramus \& Vaccaro, 2017), ter uma cultura orientada para o social (Di Domenico et al., 2010; Henry, 2015; Altinay et al., 2016; Srivetbodee et al., 2017; Ramus \& Vaccaro, 2017), reformular valores voltados à missão social, adaptar práticas de gestão e apoiar a reformulação de mentalidades coletivas éticas e sustentáveis as imagens de mercado (Altinay et al., 2016). Com isso, as estratégias da organização precisam estar voltadas para esse sentido, buscando sempre o equilíbrio entre a missão social e a geração de valor econômico, para assim, potencializar o desenvolvimento de um resultado positivo.

A quinta e última categoria, nomeada de marketing, envolve todos os aspectos que de algum modo satisfazem às necessidades dos consumidores, identificando solução de problemas e desejos ainda não concretizados. A partir desse entendimento, entende-se que o processo de criar, de comunicar, de entregar e de divulgar permeia essa área. É ainda considerada um campo que tem a capacidade de criar e entregar valor e que abrange diretamente o consumidor final. Desse modo, a

Revista de Gestão Social e Ambiental - RGSA, São Paulo, v. 13, n. 2, p. 75-92, maio/ago. 2019. 
primeira atitude refere-se à criação do produto, execução de projetos ou serviços que atendam às necessidades da comunidade. Assim, constata-se, a partir dos estudos, que os produtos, serviços ou atividades precisam aliviar os principais problemas sociais, bem como, ao longo do tempo, passar por melhorias. O problema deve ser algo real e ter demanda considerável, logo nota-se que se não há demanda para o produto, consequentemente não haverá criação de valor social (Yang et al., 2010; Ramus \& Vaccaro, 2017; Srivetbodee et al., 2017). 


\begin{tabular}{|c|c|c|c|c|c|}
\hline Autor (es) & Stakeholders & $\begin{array}{l}\text { Mobilização de } \\
\text { recursos }\end{array}$ & Inovação & $\begin{array}{l}\text { Planejamento } \\
\text { estratégico }\end{array}$ & Marketing \\
\hline $\begin{array}{l}\text { Ramus e Vaccaro } \\
\qquad(2017)\end{array}$ & $\begin{array}{l}\text { Comprometimento } \\
\text { de múltiplas partes } \\
\text { interessadas } \\
\text { Critérios normativos } \\
\text { para seleção de } \\
\text { parceiros } \\
\text { Capacidade de atrair } \\
\text { parceiros com } \\
\text { habilidades e } \\
\text { capacidades } \\
\text { crescentes } \\
\text { Diálogo com as } \\
\text { partes interessadas } \\
\text { Aquisição } \\
\text { habilidades técnicas } \\
\text { e gerenciais das } \\
\text { partes interessadas } \\
\text { Legitimidades e } \\
\text { reconhecimento } \\
\text { perante os atores do } \\
\text { ecossistema social }\end{array}$ & $\begin{array}{l}\text { Gerenciamento de } \\
\text { recursos humanos } \\
\text { Integração de recursos }\end{array}$ & Não mencionado & $\begin{array}{c}\text { Equilíbrio entre } \\
\text { a missão social e } \\
\text { o valor } \\
\text { econômico } \\
\text { Controle das } \\
\text { pressões internas } \\
\text { e externas } \\
\text { Cultura } \\
\text { orientada para o } \\
\text { social } \\
\text { Reformulação } \\
\text { dos valores } \\
\text { voltados à } \\
\text { missão social } \\
\text { Práticas de } \\
\text { gestão de } \\
\text { recursos } \\
\text { humanos }\end{array}$ & $\begin{array}{c}\text { Realização de projetos/ } \\
\text { produtos/serviços alinhados } \\
\text { à área social } \\
\text { Mensuração do impacto } \\
\text { Divulgação dos resultados } \\
\text { de mensuração }\end{array}$ \\
\hline $\begin{array}{c}\text { Srivetbodee, Igel e } \\
\text { Kraisornsuthasinee } \\
\qquad(2017)\end{array}$ & $\begin{array}{l}\text { Alavancagem de } \\
\text { parcerias } \\
\text { Interação com } \\
\text { consumidores por } \\
\text { meio de atividades } \\
\text { experimentais } \\
\text { Rede de contatos: } \\
\text { setor privado, setor } \\
\text { governamental, setor } \\
\text { sem fins lucrativos e } \\
\text { outras empresas } \\
\text { sociais }\end{array}$ & Integração de recursos & $\begin{array}{l}\text { Capacidade de } \\
\text { inovar } \\
\text { A inovação e o } \\
\text { desenvolvimento } \\
\text { de produtos } \\
\text { como uma } \\
\text { maneira de obter } \\
\text { valor social }\end{array}$ & $\begin{array}{c}\text { Equilíbrio entre } \\
\text { a missão social e } \\
\text { o valor } \\
\text { econômico }\end{array}$ & $\begin{array}{c}\text { Desenvolvimento de } \\
\text { produtos alinhados com a } \\
\text { missão organizacional } \\
\text { Os produtos precisam } \\
\text { aliviar os principais } \\
\text { problemas sociais e passar } \\
\text { por melhorias } \\
\text { Usabilidade de recursos } \\
\text { inexplorados por outras } \\
\text { organizações } \\
\text { Distribuição de produtos } \\
\text { por meio de canais de } \\
\text { mercado } \\
\text { Comunicação da missão } \\
\text { social e conscientização } \\
\text { Priorização do consumo } \\
\text { local dentro da comunidade }\end{array}$ \\
\hline $\begin{array}{c}\text { Mirosa, Mainvil, H } \\
\text { orne e Mangan- } \\
\text { Walker (2016) }\end{array}$ & $\begin{array}{l}\text { Participação de } \\
\text { agências com } \\
\text { diferentes agendas } \\
\text { trabalhem juntas e } \\
\text { criem valor social } \\
\text { por meio de } \\
\text { relacionamentos } \\
\text { ganha-ganha. }\end{array}$ & Não foi mencionado & $\begin{array}{l}\text { Não foi } \\
\text { mencionado }\end{array}$ & $\begin{array}{l}\text { Não foi } \\
\text { mencionado }\end{array}$ & Não foi mencionado \\
\hline $\begin{array}{l}\text { Altinay, Sigala e } \\
\text { Waligo (2016) }\end{array}$ & $\begin{array}{l}\text { Envolvimento e } \\
\text { colaboração de } \\
\text { partes interessadas } \\
\text { Desenvolvimento de } \\
\text { relacionamento } \\
\text { Fomento ao diálogo } \\
\text { entre as partes } \\
\text { interessadas } \\
\text { Trocas e integração } \\
\text { de recursos entre os } \\
\text { atores } \\
\text { Capital social } \\
\text { (construção de } \\
\text { relações de boa } \\
\text { qualidade) } \\
\text { Empoderamento da } \\
\text { comunidade local } \\
\text { Criação de confiança } \\
\text { entre as partes } \\
\text { Formação de redes } \\
\text { de contatos }\end{array}$ & $\begin{array}{l}\text { Capital social } \\
\text { (construção de } \\
\text { relações de boa } \\
\text { qualidade) } \\
\text { Desenvolvimento do } \\
\text { capital cognitivo } \\
\text { Capacitação de } \\
\text { colaboradores } \\
\text { Financiamento } \\
\text { monetário ou físico } \\
\text { Adaptação e } \\
\text { integração recursos } \\
\text { Capacidade de extrair } \\
\text { recursos do contexto } \\
\text { local } \\
\text { Acesso a recursos } \\
\text { financeiros e técnicos } \\
\text { para inovar e criar } \\
\text { valor social }\end{array}$ & $\begin{array}{l}\text { Capacidade de } \\
\text { adaptação }\end{array}$ & $\begin{array}{c}\text { Suporte a } \\
\text { reformação de } \\
\text { mentalidades } \\
\text { coletivas éticas e } \\
\text { sustentáveis e } \\
\text { imagens de } \\
\text { mercado } \\
\text { Adaptar as } \\
\text { práticas de } \\
\text { gestão }\end{array}$ & $\begin{array}{l}\text { Desenvolvimento de novos } \\
\text { produtos }\end{array}$ \\
\hline
\end{tabular}




\begin{tabular}{|c|c|c|c|c|c|}
\hline Henry (2015) & $\begin{array}{l}\text { Os parceiros } \\
\text { compartilharem uma } \\
\text { missão social } \\
\text { Participação de } \\
\text { outros atores sociais } \\
\text { Identificação de } \\
\text { organizações } \\
\text { parceiras com } \\
\text { objetivos } \\
\text { semelhantes e } \\
\text { recursos } \\
\text { complementares } \\
\text { Abordagem } \\
\text { colaborativa é } \\
\text { necessária }\end{array}$ & $\begin{array}{c}\text { Compartilhamento de } \\
\text { recursos } \\
\text { Gerenciamento dos } \\
\text { recursos } \\
\text { Agrupamento de } \\
\text { recursos } \\
\text { Financiamentos }\end{array}$ & $\begin{array}{l}\text { Mudanças } \\
\text { criativas são } \\
\text { necessárias }\end{array}$ & $\begin{array}{c}\text { Equilíbrio entre } \\
\text { a missão social e } \\
\text { o valor } \\
\text { econômico }\end{array}$ & Não foi mencionado \\
\hline $\begin{array}{l}\text { Wilson e Post } \\
\quad \text { (2013) }\end{array}$ & $\begin{array}{l}\text { Integração de grupo } \\
\text { beneficiário } \\
\text { pretendido na cadeia } \\
\text { de valor em um } \\
\text { estágio inicial } \\
\text { Integração de grupo } \\
\text { de partes } \\
\text { interessadas }\end{array}$ & $\begin{array}{l}\text { Benefício econômico } \\
\text { para investidores, } \\
\text { proprietários e } \\
\text { empregados } \\
\text { O dinheiro é coerente } \\
\text { com o ato de criar } \\
\text { valor (econômico e } \\
\text { social) para uma } \\
\text { ampla gama de partes } \\
\text { interessadas }\end{array}$ & Não mencionado & $\begin{array}{c}\text { Construção de } \\
\text { um modelo de } \\
\text { negócio voltado } \\
\text { à missão social } \\
\text { Cadeia de valor } \\
\text { que possibilite a } \\
\text { realização de } \\
\text { uma missão } \\
\text { social } \\
\text { Abordagem } \\
\text { baseada no } \\
\text { mercado }\end{array}$ & $\begin{array}{c}\text { A natureza da mudança } \\
\text { social está embutida e } \\
\text { acontece como resultado do } \\
\text { produto ou serviço } \\
\text { principal. }\end{array}$ \\
\hline $\begin{array}{c}\text { Di Domenico, } \\
\text { Haugh e Tracey } \\
\text { (2010) }\end{array}$ & $\begin{array}{l}\text { Envolvimento de } \\
\text { partes interessadas } \\
\text { na gestão, criação e } \\
\text { governaç̧a } \\
\text { Envolvimento de } \\
\text { membros da } \\
\text { comunidade local na } \\
\text { tomada de decisão e } \\
\text { governança } \\
\text { organizacional } \\
\text { Persuasão de outras } \\
\text { partes interessadas } \\
\text { para alavancar a } \\
\text { aquisição de novos } \\
\text { recursos e apoio }\end{array}$ & $\begin{array}{c}\text { Criação dinâmica de } \\
\text { recursos } \\
\text { Resposta tática } \\
\text { necessária a pressão } \\
\text { da escassez de } \\
\text { recursos } \\
\text { Recombinam os } \\
\text { recursos existentes de } \\
\text { maneira inovadora }\end{array}$ & $\begin{array}{c}\text { Capacidade de } \\
\text { inovar } \\
\text { Capacidade de } \\
\text { adaptação e } \\
\text { improvisação } \\
\text { conforme } \\
\text { necessidades } \\
\text { sociais e } \\
\text { ambientais } \\
\text { Inovar no } \\
\text { modelo de } \\
\text { negócios } \\
\text { Maneiras } \\
\text { inovadoras para } \\
\text { resolver } \\
\text { problemas e } \\
\text { responder a } \\
\text { oportunidades }\end{array}$ & $\begin{array}{c}\text { Estratégia de } \\
\text { bricolagem } \\
\text { (fazer com o que } \\
\text { tem) } \\
\text { A adoção de } \\
\text { estratégias que } \\
\text { envolvam "testar } \\
\text { as coisas" para } \\
\text { gerar valor } \\
\text { social }\end{array}$ & $\begin{array}{c}\text { Reutilização de materiais } \\
\text { indesejáveis descartados } \\
\text { por outras } \\
\text { Experimentar soluções } \\
\text { Execução de vários } \\
\text { projetos e serviços que } \\
\text { atendam às diversas } \\
\text { necessidades da } \\
\text { comunidade }\end{array}$ \\
\hline $\begin{array}{l}\text { Yang, Ben Wu, } \\
\text { Su, Kao e Lin } \\
\quad(2010)\end{array}$ & $\begin{array}{l}\text { Integração com seus } \\
\text { parceiros } \\
\text { estratégicos para } \\
\text { formar alianças } \\
\text { Integração de } \\
\text { habilidades internas, } \\
\text { recursos e processos } \\
\text { com parceiros } \\
\text { externos } \\
\text { Estratégias de } \\
\text { cooperação para } \\
\text { construir rede de } \\
\text { valor forte e } \\
\text { desenvolver parceria } \\
\text { e alianças } \\
\text { Formação de } \\
\text { alianças estratégicas }\end{array}$ & $\begin{array}{l}\text { Treinamento } \\
\text { educacional para os } \\
\text { colaboradores }\end{array}$ & $\begin{array}{l}\text { Capacidade de } \\
\text { se adaptar } \\
\text { Espírito de } \\
\text { inovação e } \\
\text { proposta de } \\
\text { valor } \\
\text { Diversificação }\end{array}$ & $\begin{array}{c}\text { Equilíbrio entre } \\
\text { a missão social e } \\
\text { o valor } \\
\text { econômico } \\
\text { Levar a missão } \\
\text { social como base }\end{array}$ & $\begin{array}{c}\text { Identificar os compradores } \\
\text { Fornecer produtos e } \\
\text { serviços inovadores } \\
\text { Adotar estratégias de } \\
\text { marketing } \\
\text { Criação de um produto } \\
\text { acessível para atender à } \\
\text { necessidade do cliente } \\
\text { Gerenciar seus canais de } \\
\text { distribuição } \\
\text { Fornecer ao público um } \\
\text { preço baixo (acessível) } \\
\text { Aprimoramento de } \\
\text { produtos } \\
\text { Marketing de experiência }\end{array}$ \\
\hline
\end{tabular}

Figura 3. Categorias identificadas a partir da rede meta-causal

Fonte: Elaborado pelos autores 
Nesse sentido, o setor de marketing de uma empresa social pode gerar e fortificar o valor por meio de atitudes pró-sociais com campanhas de marketing para melhorar a reputação da organização. As campanhas de divulgações, seja por meio de livros, artigos, relatórios, boletins informativos, ajudam as empresas a serem vistas pelos stakeholders externos e internos, podendo comunicar seus compromissos sociais aos seus beneficiários. O objetivo da divulgação de informações auxilia a desencadear um processo interno de criação de sentido para o reforço e a reintegração de valores e objetivos pró-sociais dentro do funcionamento de organizações (Ramus \& Vaccaro, 2017; Srivetbodee et al., 2017). Além da divulgação, as empresas sociais precisam ter canais de distribuição para dimensionar o seu produto a fim de que ele chegue até o consumidor final (Yang et al., 2010; Srivetbodee et al., 2017).

Assim, com a configuração dessas categorias, criou-se a Figura 4 que representa os cinco elementos que as empresas sociais podem desenvolver no seu âmbito organizacional para criar e potencializar a criação de valor social.

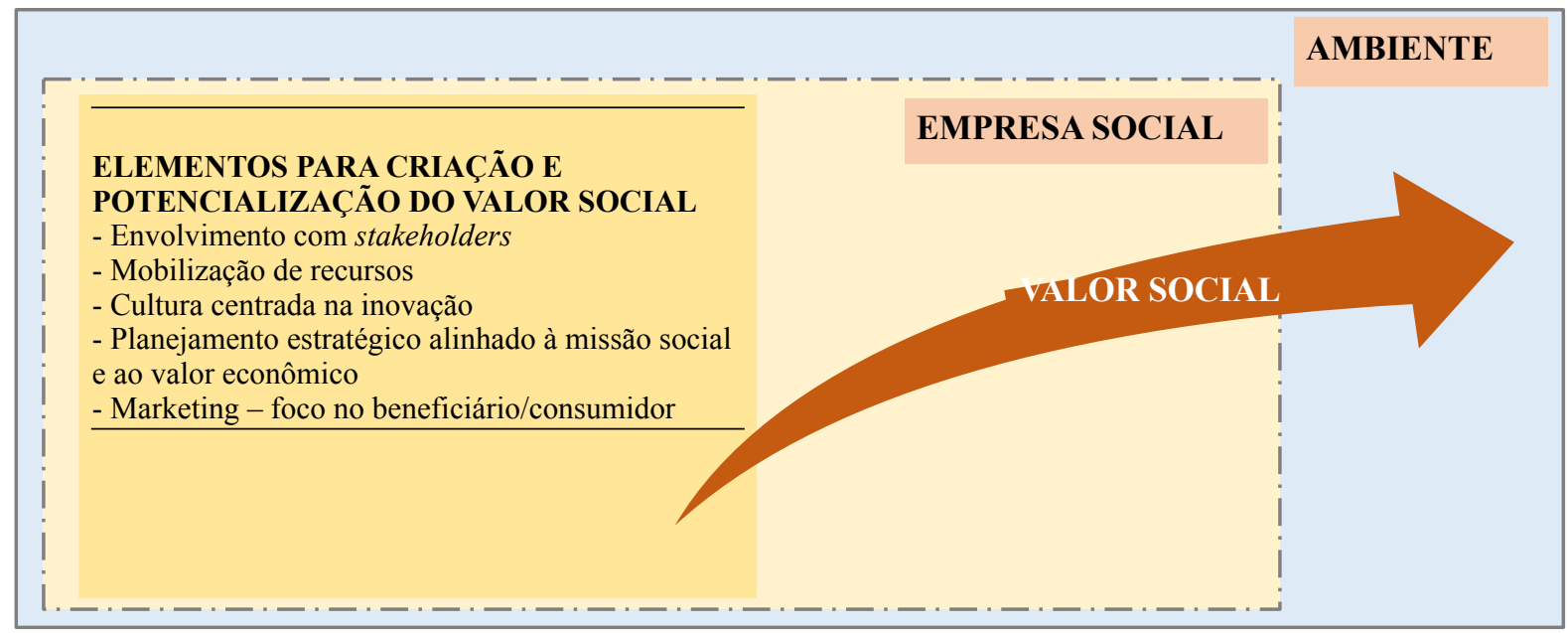

Figura 4. Criação e potencialização do valor social pelas empresas sociais Fonte: Os autores (2018)

É fundamental destacar a existência dos cinco elementos para que o valor social seja criado e potencializado. Esses elementos devem ser desenvolvidos comumente dentro da organização, tendo em vista que eles estão interligados.

\section{Discussão dos resultados}

$\mathrm{Na}$ oitava etapa, a partir da análise dos artigos, compreendeu-se que, embora a frequência em que o termo valor social seja citado na área de empresas sociais, o seu processo de criação não é tão fácil. Portanto, para lidar com esse desafio, pesquisas constataram a necessidade das empresas junto aos seus empreendedores, desenvolverem competências e habilidades capazes de se mostrar mais eficientes em um ambiente repleto de pressões no processo de criação de valor social (Yang et al., 2010; Rammo \& Vaccaro, 2017). Além disso, comprovaram a dificuldade que as empresas sociais possuem em potencializar e dimensionar o impacto positivo gerado principalmente à sociedade (Srivetbodee et al., 2017). Desse modo, considerado ainda uma abordagem pouco explorada e que gera conflitos conceituais e práticos, desenvolveu-se nessa pesquisa cinco elementos que levam as empresas sociais a criarem e a potencializarem o seu valor social. 
O primeiro elemento, engajamento dos stakeholders, se mostrou importante nos estudos de casos investigados por demonstrar a relevância de atores internos e externos próximos à organização no processo de criação de valor social (Silva \& Wright, 2019). Evidências sugerem que quanto maior a aproximação desses atores, seja para formação de redes, cluters, parcerias, contatos, colaborações, alianças e cooperações, maior é a possibilidade de alcançar seus objetivos sociais (Collazzo-Yelpo \& Kubelka, 2019; Kolk \& Lenfant, 2015). Portanto, tem-se que o engajamento e a interação com stakeholders pode ser um elemento facilitador no desenvolvimento de novas ideias e fechamento de acordos importantes, contribuindo na criação de valor social.

O segundo elemento, mobilização de recursos, sugere que as empresas sociais possuem dificuldades na obtenção desses ativos, mas podem superar a partir da utilização de recursos descartados, negligenciados e combinados, além de estabelecer parcerias como forma de acessar a tecnologias e recursos disponíveis (Quelin, Kivleniece \& Lazzarini, 2017). Evidências sinalizam que a criação de valor social somente é possível quando as organizações sociais mobilizam e gerenciam recursos, sejam eles humanos, financeiros, tecnológicos, naturais (Turker \& Vural, 2017). Com isso, compreende-se que a mobilização de recursos por parte das empresas sociais auxilia no desenvolvimento organizacional e na criação de produtos inovadores, contribuindo na criação de valor social.

O terceiro elemento, inovação, está integralmente relacionado ao valor social criado pelas empresas sociais (Dwivedi \& Weerawardena, 2018). Indícios teóricos apontam que a inovação social gera esse valor (Van Der Have \& Rubalcaba, 2016; Chell, Nicolopoulou \& Karataş-Özkan, 2010), por envolver a promoção de algo transformador e novo que surge para mudar a vida das pessoas para melhor, não oferecendo-lhes somente o básico, mas qualidade de vida e bem-estar. Assim, propõe-se que uma cultura centrada na inovação remete a criação de produtos/serviços ou atividades inovadoras que atendam necessidades sociais, promovendo a criação de valor.

O quarto elemento, planejamento estratégico alinhado à missão social e ao valor econômico, é entendido como aspecto primordial para as empresas sociais. Pensar em equilibrar esses dois valores facilita o progresso social, pois o foco somente no valor social, resulta em dimensionamento mais lento do sucesso da empresa (Collazzo-Yelpo; Kubelka, 2019; Jetzek; Avital; Bjorn-Andersen, 2014). A sustentabilidade financeira é relevante para manter o caráter social da organização (RidleyDuff \& Bull, 2006; Domenico, Haugh \& Tracey, 2010). Assim, preconiza-se que as estratégias da organização precisam voltar-se a esse sentido, buscando sempre o equilíbrio entre a missão social e a geração de valor econômico, para potencializar o desenvolvimento de um resultado positivo. Em outros termos, o valor social não pode ser desassociado do valor econômico, pois estão diretamente interligados.

O quinto elemento, marketing, é entendido como o aspecto que dimensiona o produto/ serviço oferecido pela empresa social. É com base nesse elemento que o produto chega mais facilmente ao consumidor, satisfazendo suas necessidades ou solucionando o seu problema. A partir do marketing, a empresa social pode criar, comunicar, entregar e divulgar o seu produto, abrangendo diretamente o consumidor final (Yang et al., 2010; Sandeep \& Ravishankar, 2015). Assim sendo, as estratégias de marketing promovem escalabilidade ao negócio, proporcionando ao beneficiário a solução para atender suas necessidades contribuindo, assim, para geração de valor social.

Desvela-se ainda, como contribuição, que a importância não está somente no resultado que é o valor social, mas, sobretudo, no processo no qual é criado. Para se compreender melhor tal entendimento, consta-se que para a empresa social gerar um resultado positivo à sociedade é preciso passar por um processo, desde o seu surgimento até o dimensionamento da sua atividade. Revela-se ainda a importância da atuação do empreendedor social como o ator principal desse processo. Embora ele não esteja como uma das dimensões do modelo proposto, permeia todas elas, além do

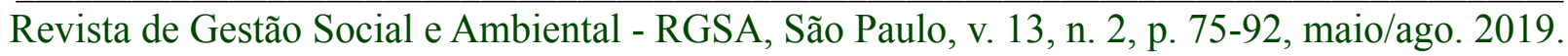


que a criação de valor social não está dentro do empreendedor social ou da empresa social, mas no sistema que ambos habitam e tentam desenvolver (Altinay et al., 2016). Portanto, o empreendedor social é imprescindível para o funcionamento do negócio, mas sem o sistema social ele não consegue alcançar a criação de valor.

\section{CONSIDERAÇÕES FINAIS}

Pretendeu-se, neste artigo, compreender como as empresas sociais criam e potencializam o seu valor social, a partir de uma meta-síntese, estratégia de pesquisa proposta por Hoon (2013). A partir dessa estratégia, oito estudos de casos qualitativos foram selecionados, sendo analisados de forma rigorosa e sistemática.

Três contribuições teóricas são esperadas com base nos achados do estudo. Primeiro, ao aprofundar o conhecimento sobre empresas sociais e valor social, é possível demonstrar mais claramente que os seus conceitos estão correlacionados, pois a motivação principal das empresas sociais é a criação do valor social, diferentemente de empresas com outros formatos organizacionais. Tal contribuição se torna importante, tendo em vista que os estudos de casos que versam sobre esses assuntos ainda não conseguiram relacionar diretamente essas duas temáticas, embora estejam propriamente associadas.

Segundo, os elementos identificados nos estudos de casos, tais como engajamento de stakeholders, mobilização de recursos, inovação, planejamento estratégico e marketing, não se apresentavam de forma explícita nos estudos de caso analisados, apresentando conclusões esparsas acerca desses dois assuntos. Portanto, ao extrair esses elementos, interpretá-los e apresentá-los de forma sistemática pode ser considerada uma contribuição com a literatura, uma vez que, além da obscuridade dessa questão, pouco se sabia quanto a esses aspectos. Terceiro, ao sintetizar a resposta do problema de pesquisa em elementos norteadores e ao criar um modelo teórico com base na nos estudos de empresa social e valor social, outros pesquisadores podem se utilizar desses resultados para investigarem esses elementos de forma isolada ou, testá-los no campo empírico. Isso poderá contribuir com o avanço da literatura da área.

Quanto ao contexto prático, percebe-se que o próprio campo permanece incerto em relação a como as empresas podem criar e potencializar o valor social. Logo, ao apresentar alguns elementos que contribuem para a geração de valor social por empresas e empreendedores sociais, este trabalho sugere maior atenção dos praticantes nas suas escolhas estratégicas e no seu processo decisório. $\mathrm{O}$ modelo conceitual aqui proposto pode ser aplicado pelos gestores, de empresas sociais de diferentes portes e setores, tendo em vista que são elementos facilitadores e propulsores para seu processo de crescimento e expansão do valor social. Assim, quando melhor empregado pela organização, mais satisfatórios poderão ser os resultados.

Além disso, pode-se discutir algumas limitações do estudo. Inicialmente, a principal restrição reside na redução de 44 estudos para a seleção de oito pesquisas. No entanto, isso deve-se particularmente a configuração do método baseado em selecionar artigos qualitativos que utilizaram a estratégia de pesquisa de estudos de caso e que façam sentido para a especificidade do objetivo central do referido estudo. Inclusive, a seleção de poucos artigos é característica da meta-síntese para se obter profundidade na análise das informações, como pode-se visualizar em outros estudos, como o de Severgnini, Takahashi e Abib (2019) com oito artigos analisados e o de Morais-da-Silva, Takahashi e Segatto (2016) com nove pesquisas selecionadas.

Ao complementar a essa justificativa, a literatura de empresas sociais e valor social ainda é recente em termos de publicações, o que se reflete em números menores de publicações quando comparados a outros campos de pesquisa na área de Administração. Dessa forma, o número pouco

Revista de Gestão Social e Ambiental - RGSA, São Paulo, v. 13, n. 2, p. 75-92, maio/ago. 2019. 
expressivo de artigos selecionados para este estudo pode ser considerada uma limitação do método empregado e do ainda recente avanço da literatura da área.

Além das contribuições e limitações, a meta-síntese permitiu vislumbrar possibilidades de pesquisas futuras dentro desse campo de análise, tendo em vista o interesse por parte dos pesquisadores. Assim, incialmente, podem ser investigados os fluxos de investimento em empresas sociais, pesquisas sobre a compreensão da lei do valor social (Samuel, White \& Jones, 2018), bem como estudar estratégias voltadas para empresa social e engajamento dos stakeholders (Ramus \& Vaccaro, 2017), analisar a influência do marketing social no desenvolvimento do valor social (Srivetbodee et al., 2017), investigar o papel das diversas capacidades de marketing das empresas sociais (Sengupta \& Sahay, 2017), e, por fim, analisar como as instituições influenciam a adoção de recursos em diferentes contextos, pesquisar a compreensão de como as empresas sociais geram valor social em contexto de países emergentes.

\section{REFERÊNCIAS}

Acs, Z. J., Boardman, M. C., \& McNeely, C. L. (2013). The social value of productive entrepreneurship. Small Business Economics, 40(3), 785-796.

Altinay, L., Sigala, M., \& Waligo, V. (2016). Social value creation through tourism enterprise. Tourism Management, 54, 404-417.

Austin, J., Stevenson, H., \& Wei-Skillern, J. (2006). Social and commercial entrepreneurship: same, different, or both? Revista de Administração, 47(3), 370-384.

Barki, E. (2015). Negócios de impacto: tendência ou modismo?. GV-executivo, 14(1), 14-17.

Battilana, J., \& Lee, M. (2014). Advancing research on hybrid organizing-Insights from the study of social enterprises. The Academy of Management Annals, 8(1), 397-441.

Chell, E., Nicolopoulou, K., \& Karataş-Özkan, M. (2010). Social entrepreneurship and enterprise: International and innovation perspectives, 22(6), 485-493.

Choi, N., \& Majumdar, S. (2014). Social entrepreneurship as an essentially contested concept: Opening a new avenue for systematic future research. Journal of business venturing, 29(3), 363-376.

Chowdhury, M. S. (2007). Overcoming entrepreneurship development constraints: the case of Bangladesh. Journal of Enterprising Communities: People and Places in the Global Economy, 1(3), 240-251.

Collazzo Yelpo, P., \& Kubelka, L. (2019). Shared value clusters in Austria. Competitiveness Review: An International Business Journal, 29(1), 61-76.

Comini, G. M. (2016). Negócios sociais e inovação social: um retrato de experiências brasileiras (Tese de livre docência). Departamento de Administração da Faculdade de São Paulo, Universidade de São Paulo.

Comini, G., Barki, E., \& de Aguiar, L. T. (2012). A three-pronged approach to social business: A Brazilian multi-case analysis. Revista de Administração, 47(3), 385-397.

Dacin, M. T., Dacin, P. A., \& Tracey, P. (2011). Social entrepreneurship: a critique and future directions. Organization science, 22(5), 1203-1213.

Dahan, N. M., Doh, J. P., Oetzel, J., \& Yaziji, M. (2010). Corporate-NGO collaboration: co-creating new business models for developing markets. Long range planning, 43(2-3), 326-342. 
Defourny, J., \& Nyssens, M. (2010). Conceptions of social enterprise and social entrepreneurship in Europe and the United States: convergences and divergences. Journal of social entrepreneurship, 1(1), 32-53.

Di Domenico, M., Haugh, H., \& Tracey, P. (2010). Social bricolage: theorizing social value creation in social enterprises. Entrepreneurship theory and practice, 34(4), 681-703.

Dwivedi, A., \& Weerawardena, J. (2018). Conceptualizing and operationalizing the social entrepreneurship construct. Journal of Business Research, 86, 32-40.

Henry, C. (2015). Doing well by doing good: opportunity recognition and the social enterprise partnership. Journal of social entrepreneurship, 6(2), 137-160.

Hoon, C. (2013). Meta-synthesis of qualitative case studies: an approach to theory building. Organizational Research Methods, 16(4), 522-556.

Islam, M. A. (2017). Disclosures of social value creation and managing legitimacy: a case study of three global social enterprises. Australian Accounting Review, 27(3), 297-314.

Jetzek, T., Avital, M., \& Bjorn-Andersen, N. (2014). Data-driven innovation through open government data. Journal of theoretical and applied electronic commerce research, 9(2), 100-120.

Knife, K. A., Haughton, A., \& Dixon, E. (2014). Measuring sustainability and effectiveness of social value creation by social sector actors/social enterprises, within developing countries. Academy of Entrepreneurship Journal, 20(1).

Lepak, D. P., Smith, K. G., \& Taylor, M. S. (2007). Value creation and value capture: a multilevel perspective. Academy of management review, 32(1), 180-194.

London, T., Anupindi, R., \& Sheth, S. (2010). Creating mutual value: lessons learned from ventures serving base of the pyramid producers. Journal of Business Research, 63(6), 582-594.

Liu, G., Eng, T. Y., \& Takeda, S. (2015). An investigation of marketing capabilities and social enterprise performance in the UK and Japan. Entrepreneurship Theory and Practice, 39(2), 267-298.

Mair, J., \& Marti, I. (2006). Social entrepreneurship research: a source of explanation, prediction, and delight. Journal of world business, 41(1), 36-44.

Márquez, P. Reficco, E., \& Berger, G. (2009). Negocios inclusivos en américa latina. Harvard business review.

Mirosa, M., Mainvil, L., Horne, H., \& Mangan-Walker, E. (2016). The social value of rescuing food, nourishing communities. British Food Journal, 118(12), 3044-3058.

Morais-Da-Silva, R. L., Takahashi, A. R. W., \& Segatto, A. P. (2016). Scaling up social innovation: a meta-synthesis. RAM. Revista de Administração Mackenzie, 17(6), 134-163.

Mulyaningsih, H. D., \& Dhewanto, W. (2013, April). In what ways does social enterprise creating the innovation. In Proceedings of the 8th Asian Business Research Conference(pp. 1-2).

Pessanha, H. (2014). O Movimento Choice e a criação de negócios de impacto no Brasil. Cadernos de Gestão e Empreendedorismo, 2(1), 01-09.

Prahalad, C. K. (2005). A riqueza na base da pirâmide. Porto Alegre: Artmed.

Quelin, B. V., Kivleniece, I., \& Lazzarini, S. (2017). Public-private collaboration, hybridity and social value: towards new theoretical perspectives. Journal of Management Studies, 54(6), 763-792.

Revista de Gestão Social e Ambiental - RGSA, São Paulo, v. 13, n. 2, p. 75-92, maio/ago. 2019. 
Ramus, T., \& Vaccaro, A. (2017). Stakeholders matter: How social enterprises address mission drift. Journal of Business Ethics, 143(2), 307-322.

Rosolen, T., Tiscoski, G. P., \& Comini, G. M. (2014). Empreendedorismo social e negócios sociais: um estudo bibliométrico da produção nacional e internacional. Revista Interdisciplinar de gestão social, 3(1).

Samuel, A., White, G. R., Jones, P., \& Fisher, R. (2018). Social enterprises operating in the South Wales valleys: a Delphi study of persistent tensions. Social Enterprise Journal, 14(1), 22-38.

Sandeep, M. S., \& Ravishankar, M. N. (2015). Social innovations in outsourcing: an empirical investigation of impact sourcing companies in India. The Journal of Strategic Information Systems, 24(4), 270-288.

Sengupta, S., \& Sahay, A. (2017). Social entrepreneurship research in Asia-Pacific: Perspectives and opportunities. Social Enterprise Journal, 13(1), 17-37.

Severgnini, E., Takahashi, A. R. W., \& Abib, G. (2019). Risk and Organizational ambidexterity: a meta-synthesis of a case study and a framework. BBR. Brazilian Business Review, 16(5), 470-499.

Silva, M., \& Wright, M. (2019). Entrepreneurial co-creation: societal impact through open innovation. $R \& D$ Management.

Singh, A. (2016). The process of social value creation: a multiple-case study on social entrepreneurship in India. Springer.

Smith, W. K., Gonin, M., \& Besharov, M. L. (2013). Managing social-business tensions: A review and research agenda for social enterprise. Business Ethics Quarterly, 23(3), 407-442.

Son, H., Lee, J., \& Chung, Y. (2017). Value creation mechanism of social enterprises in manufacturing industry: Empirical evidence from Korea. Sustainability, 10(1), 46.

Srivetbodee, S., Igel, B., \& Kraisornsuthasinee, S. (2017). Creating social value through social enterprise marketing: case studies from thailand's food-focused social entrepreneurs. Journal of Social Entrepreneurship, 8(2), 201-224.

Turker, D., \& Vural, C. A. (2017). Embedding social innovation process into the institutional context: voids or supports. Technological Forecasting and Social Change, 119, 98-113.

Van der Have, R. P., \& Rubalcaba, L. (2016). Social innovation research: an emerging area of innovation studies? Research Policy, 45(9), 1923-1935.

Wilson, F., \& Post, J. E. (2013). Business models for people, planet (\& profits): exploring the phenomena of social business, a market-based approach to social value creation. Small Business Economics, 40(3), 715-737.

Yang, M. H., Wu, J. T. B., Su, C. J., Kao, T. Y., \& Lin, C. C. (2010). The study of social enterprise management. International Journal of Revenue Management, 4(2), 145-162.

Yunus, M., Moingeon, B., \& Lehmann-Ortega, L. (2010). Building social business models: lessons from the Grameen experience. Long range planning, 43(2-3), 308-325. 